\title{
Does State Allocation of University Funding Moderate Effectively Maintained Inequality?
}

Christian Michael Smith

University of California, Merced

Department of Sociology

\section{Funding:}

The research reported here was supported by the Institute of Education Sciences, U.S. Department of Education, through Award \#R305B150003 to the University of WisconsinMadison. The opinions expressed are those of the author and do not represent views of the U.S. Department of Education.

This work was also supported by a grant from the U.S. Department of Education, Institute for Education Sciences to the Wisconsin Department of Public Instruction (R372A 150031). Any views, opinions, findings, or conclusions expressed in this paper are those of the author and do not necessarily reflect the views of the Institute for Education Sciences, the Department of Public Instruction, WCER, or cooperating institutions.

\section{Acknowledgments:}

I am grateful for comments on previous drafts of this manuscript that I received from Eric Grodsky, Felix Elwert, Monica Grant, Jordan Conwell, Nick Hillman, and Noah Hirschl. 


\begin{abstract}
According to the theory of Effectively Maintained Inequality (EMI), economically advantaged individuals not only enter each level of education at higher rates than do their less advantaged peers, but also enjoy qualitative advantages at each level that position them more favorably to continue to the next level. Governments may play a role in facilitating or limiting EMI because they allocate appropriations to public universities; the more between-university variability in these funds, the more horizontal differences high-income students may exploit. I ask whether Wisconsin's unequal pattern of appropriations across its institutions of higher education exacerbates income-based disparities in college persistence. I test two hypotheses: (1) Economically advantaged students sort into the universities with greatest appropriations; (2) Appropriations promote first-to-second-year persistence. Evidence in favor of both hypotheses would support the claim that an unequal pattern of appropriations exacerbates college persistence disparities and, accordingly, suggest that unequal allocation facilitates EMI. Results support hypothesis (1) but not hypothesis (2). The results do not present evidence that the Wisconsin state government facilitated or limited EMI based on its allocation of funds across universities.
\end{abstract}

\title{
Keywords
}

Social stratification, sociology of education, higher education, inequality, college persistence, university finance 


\section{Introduction}

This study concerns the potential link between horizontal educational stratification and state governmental policy. The distinction between vertical and horizontal educational stratification is foundational in the sociology of education. Vertical stratification arises when advantaged groups enter a given level of education at greater rates than disadvantaged groups, while horizontal stratification arises when advantaged students at that level receive a qualitatively superior education that better promotes advancement to the next level of education (Gerber and Cheung 2008). While scholars of social stratification have documented horizontal stratification in postsecondary education (Andrew 2017; Roksa et al. 2007), the field knows less about how policies, especially state governmental policies, mitigate this form of stratification.

The unequal outcome of interest in this study is the economic college persistence gap, which is very wide in the United States. Economically disadvantaged students' college completion rates have proven stubbornly meager (Kelchen 2017), and as is clear from many years of research, dropout before the second year is a substantial contributing factor (Shapiro et al. 2014; Smith 1995). Pell grant recipients' six-year graduation rate is now about ten percentage points lower than that of students not receiving the grants (Kelchen 2017). College persistence disparities are pragmatically important, first, because college confers private benefits like better wages (Webber 2016) and health (Cutler and Lleras-Muney 2006), and second, because collegeeducated individuals bring public benefits like increased tax revenue and civic engagement (Baum, Ma, and Payea 2013).

Despite how persistence gaps have endured, most states rolled back their funding of postsecondary education after the Great Recession (Ma et al. 2015), causing universities to compete for an increasingly scarce pool of money. States usually end up funding some 
universities far more generously than others. It may matter how states allocate appropriations across universities because this allocation may affect which universities can afford the academic support, instructional, and student service expenditures that research shows promote persistence (Gansemer-Topf and Schuh 2006; Ryan 2004; Webber and Ehrenberg 2010). If state appropriations promote persistence, and if economically advantaged students tend to attend the universities with the greatest state appropriations, then an uneven allocation of state appropriations exacerbates persistence gaps by channeling funds to the universities that serve economically advantaged students.

To test the role that state governments' allocation of university funding plays in horizontal stratification, I test two hypotheses using data from Wisconsin: (1) Economically advantaged students sort into the universities with the greatest per-student state appropriations, and (2) Increased state appropriations promote first-to-second-year persistence. The evidence supports Hypothesis (1): compared to the most economically advantaged students, the least economically advantaged students attend Wisconsin public universities that receive an average of $\$ 600$ less in per-student state appropriations. However, the evidence does not support Hypothesis (2): I precisely estimate a very small impact of university-level changes in state appropriations on student persistence. I then attempt to explain this null result by showing that university-level changes in state appropriations have little impact on academic support expenditures, the type of expenditures that matter most for persistence in Wisconsin. I situate the results within Lucas's (2001) framework of Effectively Maintained Inequality (EMI), which formalizes a particular theory of horizontal stratification. I argue that the results do not present evidence that the Wisconsin state government facilitated or limited EMI based on its pattern of state appropriations to universities. 


\section{Background}

\subsection{Theoretical Framework: Effectively Maintained Inequality}

Drawing on educational transitions literature (Mare 1980; Raftery and Hout 1993) and high school tracking literature (Gamoran and Mare 1989; Hallinan 1992), Lucas (2001) finds that socioeconomically advantaged students reinforce inequality in educational advancement by taking college-preparatory high school courses that increase the probability of progressing to the next grade. On the basis of this finding, Lucas proposes that high-SES groups secure vertical educational advantages when such advantages are commonly possible and secure horizontal educational advantages when such advantages are commonly possible. Because this theory implies that the highest socioeconomic echelons maintain horizontal educational advantages even in the absence of vertical stratification at a given level of education, Lucas calls his theory Effectively Maintained Inequality.

Since Lucas posed his theory, several social scientists have presented evidence that universities differ in the extent to which they promote school continuation, in an analogous fashion to that of high school curricula. Cunha and Miller (2014) find that the postsecondary institution one attends has a substantial conditional association with both graduation and first-tosecond year persistence. Furthermore, net of many student characteristics, selective colleges graduate their students at a higher rate than do their less selective counterparts (Bowen, Chingos, and McPherson 2009; Small and Winship 2007). Institutions with greater expenditures on academic support (Gansemer-Topf and Schuh 2006; Ryan 2004), instruction, and student services (Webber and Ehrenberg 2010) also seem to promote student persistence and graduation. To the extent that high-SES individuals are overrepresented in the best institutions — which is the case at minimum when proxying institutional quality with selectivity (Roksa et al. 2007)_- 
variation in educational quality exacerbates college persistence disparities. Thus, it is unsurprising that Andrew (2017) finds support for EMI in what is, to my knowledge, the only explicit test of EMI at the postsecondary level.

Neo-Weberian theory can help illuminate how high-socioeconomic status individuals effectively maintain inequality. Social closure denotes how groups maximize their accumulation of rewards by limiting resources to out-group members (Parkin 1979). In the postsecondary education setting, high-SES families can in some cases achieve social closure by defining the exclusion criteria at coveted universities. For example, high-SES families have at times lobbied for selective college admissions practices, like legacy admissions, that favor the attributes of their own class (Karabel 2006). Arguably more important, though, is a process that Parkin (1979) calls adaptation. Adaptation describes the ways high-SES families leverage their resources to successfully react to the exclusion criteria society hands them, be those criteria based on test scores (Alon 2009), qualitative and extracurricular merits (Thomsen 2018), or other factors. In recent decades, standardized test scores have played an increasingly important role in U.S. college admissions (Alon and Tienda 2007). Alon (2009) argues that, as college admissions became more competitive and as admissions decisions were increasingly a function of test scores, high-SES families adapted by bolstering their edge in test scores. She proposes several mechanisms through which high-SES parents may have accomplished this adaptation, including assisting their children with academic activities and high school course selection, buying their children test preparation aids such as tutors (cf. Briggs, 2001), and communicating high educational expectations for their children early on. Mechanisms such as these may explain how the high-SES effectively maintain inequality in postsecondary education. Even within pubic university systems in a single state like Wisconsin, high-SES families may be best positioned to 
adapt to the exclusion criteria present at the most selective public universities, and this adaptation may be especially consequential in states where public universities are highly dispersed in their levels of selectivity.

\subsection{Differentiation}

Differentiation in postsecondary education facilitates EMI at the postsecondary level. A system of postsecondary education is highly differentiated if the institutions within it vary widely in how efficaciously they beget desired assets for their students. The most obvious asset that postsecondary institutions can help their students acquire is an educational credential. Therefore, given the previously reviewed evidence that institutions vary in how much they promote college persistence and graduation, the U.S. system of postsecondary education is highly differentiated.

Differentiation facilitates EMI because high-SES individuals can more easily secure horizontal advantages in postsecondary education if such advantages are available to secure based on which institution one attends. In the framework of EMI, the more horizontal advantages are commonly possible for high-SES individuals, the more one expects that they will seize these advantages. The international body of research on differentiation supports this expectation: systems of postsecondary education with the most differentiation see the greatest horizontal stratification in the postsecondary destinations of high- and low-SES students (Ayalon et al. 2008; Boliver 2011; Shavit, Arum, and Gamoran 2007; Thomsen 2015), even if the lowest-tier institutions in highly differentiated systems play an inclusive role (Shavit et al. 2007).

Governments may play a role in differentiating their postsecondary education systems because they directly allocate funds to institutions. In U.S. public postsecondary education, the task of differentiating institutions via nonuniform funding falls mostly on state governments, 
which allocate blocks of money to each public postsecondary institution in their respective states. Historically and during the period presently studied, state appropriations were the greatest source of revenue at most public institutions, though tuition revenue now rivals state appropriations as both constitute about $46 \%$ of revenue (State Higher Education Executive Officers Association 2019). The share of revenue coming from net tuition varies considerably across states $-17.5 \%$ at the low end in Wyoming and 87\% at the other end in Vermont_-with Wisconsin falling near the average at a 50\% share. If generous state appropriations give institutions the resources to promote student persistence, then a state government helps differentiate its system of postsecondary education when it allocates appropriations unevenly across institutions.

\subsection{Why Might State Appropriations Impact Persistence?}

Why might more state appropriations promote first-to-second year persistence? First, increased per-student revenue from state appropriations could allow the institution to bolster its academic support, for example by hiring and retaining more academic advisors. Academic advisors may be especially important in helping students progress during the first year, when they are especially likely to lack other mentors and forms of guidance. Second, institutions may use additional revenue from state appropriations to offer more courses per student. With smaller class sizes, students are likely to have more favorable impressions of their classes (Cuseo 2007), potentially promoting persistence as a result. Finally, institutions may use additional revenue from state appropriations to boost their student support services, including tutoring programs, counseling services, and general health services. High expenditures on student support services seem to promote persistence, especially at institutions with a high share of low-income students, who plausibly benefit more from these services if they tend to have heightened academic or 
socioemotional needs (Webber and Ehrenberg 2010). Of course, not all revenue from increased appropriations may necessarily go toward expenses that promote student persistence. For example, institutions that direct a large share of their money toward administration harm student persistence (Titus 2006). Nevertheless, national evidence from economists on the effects of statewide reductions in appropriations (rather than between-institution disparities therein) points to a substantial effect of state appropriations on persistence and graduation: Bound, Braga, Khanna, and Turner (2019) estimate that a 10\% statewide drop in appropriations leads to a 3.6\% drop in bachelor's degree production at research universities and Deming and Walters (2018) estimate that a movement from the $25^{\text {th }}$ to the $75^{\text {th }}$ percentile of state support causes a $5 \%$ increase in degrees and certificates awarded in the state. These findings suggest that, at the national level, institutions apply at least some state appropriations toward educationallyconducive efforts.

On the other hand, state appropriations may promote persistence but appear not to due to statistical artifacts. For example, if Wisconsin tends to grant more appropriations to universities during periods when they are struggling with other forms of revenue, then increases in state appropriations might not be associated with increases in overall funds that the university can wield. More generally, any unobserved factor that is associated with increases in state appropriations and decreases in persistence rates, or vice versa, will make it appear that state appropriations are less beneficial to persistence than they really are.

\subsection{State Appropriations in Wisconsin}

The Wisconsin state government allocates funding very unevenly across its public, fouryear universities. This pattern is most pronounced when comparing the flagship campus, 
Madison, to the other twelve campuses. Madison typically receives around $\$ 11,000$ per full time equivalent student in state appropriations, while almost every other campus receives less than half of that amount (calculations my own, drawn from the Integrated Postsecondary Education Data System) ${ }^{1}$.

To the extent that 1) state appropriations promote college persistence, and 2) economically advantaged Wisconsinites sort into the institutions with the greatest state appropriations, there is evidence that Wisconsin's unequal allocation of appropriations exacerbates income-based disparities in college persistence. Furthermore, this result would suggest that state governments facilitate EMI when they allocate university funding highly unequally across universities, and mitigate EMI when they allocate funding more evenly ${ }^{2}$.

Formally, the Madison campus is a bit more economically exclusive than the other twelve campuses because its tuition and fees are the greatest $-\$ 10,725$ annually vs. $\$ 7,422$ at the least expensive campus (University of Wisconsin System 2020). Formal economic exclusion is not a necessary condition for unequal access, though: It is possible that the especially selective admissions criteria of the Madison campus excludes the bulk of economically disadvantaged students from attending. Economically advantaged individuals could then disproportionately

\footnotetext{
${ }^{1}$ Some of the between-university disparity likely arises because of differential proportions of graduate students across universities, with the Madison campus having the greatest proportion. Unfortunately, it is challenging to precisely separate spending on undergraduate students from spending on graduate students (Urban Institute 2017) and IPEDS does not attempt to do so. In light of this issue, the amount of money from state appropriations that each university applies toward the average undergraduate student is not perfectly apparent, and the difference in perstudent state appropriations between Madison and the other campuses is an upper bound on the difference in perundergraduate state appropriations applied toward undergraduates.

${ }^{2}$ EMI can operate even if Wisconsin's allocation of appropriations does not exacerbate the process. Notably, this would be the case if economically advantaged students were more likely than disadvantaged students to attend highquality private and out-of-state institutions. The present study is less interested in whether EMI operates in postsecondary education and more interested in the role state distribution of postsecondary funding does or does not play in mitigating EMI.
} 
secure spots at the Madison campus by adapting to exclusion criteria that are formally classneutral.

\section{Methods}

\subsection{Data Sources}

Data come from a unique merger of three sources: the Wisconsin Statewide Longitudinal Data System (WSLDS), the National Student Clearinghouse (NSC), and the Integrated Postsecondary Education Data System (IPEDS). For student-level data, I merge WSLDS with NSC. WSLDS records academic and demographic information on every student in Wisconsin public K-12 schools, while NSC is a national data source that tracks where and when individuals enroll in postsecondary education. For institution-level data, I use IPEDS, which longitudinally records information on postsecondary institutions, including information on finances, student enrollment, and admissions. All institutions that participate in federal student aid programs must report to IPEDS, and thus IPEDS covers virtually every institution of postsecondary education in the United States. Prior research on the impacts of state appropriations uses university- or statelevel data only (Bound et al. 2019; Deming and Walters 2018a; Zhang 2009), making it difficult to study how financial factors influence different student subgroups to varying degrees. The data merger in this study facilitates such analyses because of the rich information it provides on individual students and the statistical power that large, population-level data provide.

The analytic sample encompasses the full population of 180,000 people who attended a Wisconsin public high school some time between the 2007-08 and 2015-16 school years, whose first postsecondary enrollment occurred during or before the 2017-2018 school year, whose first postsecondary enrollment was at a UW four-year campus, and who have observed ACT scores. 
Within the analytic sample, there are no missing values to impute, due to the administrative nature of the data.

\subsection{Effect of State Appropriations}

Measures. The outcome variable is a binary indicator of college persistence, operationalized as whether the student enrolled in an institution of postsecondary education the academic year following their first enrollment in postsecondary education. I measure the outcome based on year-to-year persistence, rather than ultimate graduation, because the independent variable, per-student state appropriations, is different for the same student during different years of attendance even at the same institution. The results presented later are not sensitive to my choice of first-to-second-year persistence rather than persistence in all years ${ }^{3}$.

The key independent variable is an institution-level measure of per-student state appropriations, as measured during the academic year that the student entered college (but inflation-adjusted with the Consumer Price Index to be expressed in 2018 dollars). State appropriations are the funds that institutions receive through acts of a state legislative body. The Wisconsin state government allocates funds to universities only every other year, with changes in total appropriations occurring when the state begins a new budget period during the summer of odd-numbered years. However, per-student state appropriations change every year because university enrollments are not constant within budget periods. Thus, both government allocations and shifts in enrollment drive changes in the independent variable (Bound and Turner 2007).

\footnotetext{
${ }^{3}$ Results from a survival analysis in which I operationalize the outcome more complexly are available upon request. In the survival analysis, I model year-to-year dropout (not just in the first year) with a complementary log-log model applied to student-year observations, censoring students who graduate, are still enrolled at a UW campus during the last year of observation, or transfer from a UW campus to an institution outside of the UW system. The results do not differ in any substantive ways from the results, presented later, from the simpler operationalization of persistence.
} 
The moderator variable is economic disadvantage, which I operationalize as the proportion of years the student is observed to have received free- or reduced-price lunch (FRPL) while attending Wisconsin K-12 public schools. Students are eligible for reduced-price lunch if their gross family income is at or below $185 \%$ of the federal poverty line, which in the $2015-16$ school year was $\$ 44,863$ of annual income for a family of four (U.S. Department of Agriculture 2015). I operationalize economic disadvantage using longitudinal information about FRPL receipt because FRPL receipt at a single point in time yields a coarser view of the material resources students enjoy: in particular, among those receiving FRPL, those who are receive it for more years tend to have lower family incomes and see worse academic outcomes compared to those who receive it for only one year (Michelmore and Dynarski 2017). I use persistently-FRPL to describe students who were always observed to receive FRPL and never-FRPL to describe students who were never observed to receive it $^{4}$.

I adjust for several student attributes to reduce potential confounding. Students who persist are different from those who do not, and characteristics that predict persistence may covary with within-institution, year-to-year changes in state appropriations. To reduce the threat of bias due to confounding factors, I control for a quadratic transformation of ACT math score ${ }^{5}$, a quadratic transformation of ACT English score ${ }^{6}$, proportion of years on FRPL, race/ethnicity

\footnotetext{
${ }^{4}$ Because students do not attend Wisconsin public schools for the same number of years, and because many students were enrolled in Wisconsin public schools before WSLDS data collection, not all students are observed for the same number of years. Only $6.2 \%$ of those in the analytic sample are observed in the WSLDS for a full twelve years, and $1.7 \%$ are observed for only one year. About half are observed for between four and seven years. Because of differential observation lengths, I measure some students' long-run economic disadvantage with more error than others'. For the purpose of these models, I assume this error is ignorable. However, if the error is classical, it will in fact lead to attenuated estimates of how economic disadvantage moderates the effect of state appropriations on persistence, without attenuating the estimated main effect of state appropriations on persistence. ${ }^{5}$ As measured by the Bayesian Information Criterion, quadratic terms for the ACT scores improve model fit substantially, more than enough to justify the loss in parsimony. Theoretically, the quadratic relation is unsurprising, given that a unit increase in academic achievement is likely to matter the least for persistence in the upper area of the academic achievement distribution, where nearly all students persist to the second year of college anyway.

${ }^{6}$ The ACT has two other subtests (in Reading and Science), but prior research shows that these subtests provide no additional predictive power when predicting college persistence (Bettinger, Evans, and Pope 2013). Estimates,
} 
(non-Hispanic white, non-Hispanic black, Hispanic, other/multiple race), sex, whether the student was ever suspended in high school, and binary high school indicators (high school fixed effects), which adjust for factors shared by all graduates of the high school, such as rurality, proximity to the nearest university, and any school compositional characteristics that are practically the same across cohorts. I assign high schools based on where students spent $12^{\text {th }}$ grade. $^{7}$

Analytic Strategy. Observational estimates of how state appropriations affect persistence are fallible for two chief reasons. First, the students most likely to persist may sort into the most generously-funded universities, and not all of the student characteristics predicting persistence may be observable to adjust. Second, years when universities are most generously funded overall may be years during which students are most inclined to persist for reasons not necessarily related to state appropriations. If either of these problems is present, then estimates of the effect that state appropriations have on persistence will be upwardly biased when using standard regression adjustment techniques that only control for student-level characteristics.

My approach is to simultaneously compare outcomes of students who entered the same institution but in different years and outcomes of students who entered college the same year but at different institutions. Perhaps most importantly, if institution-level differences in students' academic skills are effectively constant over the period of study, then this approach adjusts for such differences without requiring error-free measures of academic skills. More generally, the strategy adjusts for all unobserved, aggregate student characteristics that, within each institution,

presented later, relating state appropriations to college persistence are the same to two decimal places when I also include quadratic transformations of ACT Reading and Science subtest scores, as is the estimated interaction between state appropriations and economic disadvantage. Therefore, I omit these two subtest scores for parsimony.

${ }^{7}$ Unfortunately, controlling for high school GPA or class rank is not possible with the data at hand. 
are practically constant over time, as well as adjusting for unobserved, secular changes in the population of UW four-year campus students across years. In particular, I estimate a logistic ${ }^{8}$ regression model of the form

$$
\log \left(\frac{p_{i j k}}{1-p_{i j k}}\right)=\alpha+\beta A_{j k}+\zeta X_{i j k}+\gamma_{j}+\delta_{k}+\varepsilon_{i j k}
$$

where $p_{i j k}$ is the probability that student $i$ at institution $j$ in year $k$ persists, $\alpha$ is an intercept term, $\beta$ is the coefficient corresponding to per-student state appropriations $A_{j k}$ at institution $j$ in year $k$, $\zeta$ is a vector of coefficients corresponding to the vector $\boldsymbol{X}_{i j k}$ of student-level explanatory variables, $\gamma_{j}$ is the fixed effect of institution $j, \delta_{k}$ is the fixed effect of year $k$, and $\varepsilon_{i j k}$ is an idiosyncratic error term $\left(\alpha, \beta, \zeta, \gamma_{j}\right.$, and $\delta_{k}$, are all parameters to be estimated). $\boldsymbol{X}_{i j k}$ contains measures of economic disadvantage, an interaction between per-student state appropriations and economic disadvantage ${ }^{9}$, and all control variables listed above.

In the foregoing analysis, I compute Liang-Zeger standard errors, adjusting for clustering by university. While the analysis draws on population-level data, inferential statistics are still necessary when estimating causal effects because only half of all potential outcomes are observed (Abadie et al. 2020). Additionally, it is necessary to adjust standard errors for clustering because, while observations are not sampled based on a cluster variable, levels of the independent variable are assigned based on one (Abadie et al. 2017).

\footnotetext{
${ }^{8}$ Because the unconditional probability of persistence is quite high (0.83), I prefer to estimate a logistic regression model rather than a linear probability model in order to prevent predicted probabilities greater than 1 . However, to demonstrate that the substantive results are not very sensitive to this functional form decision, I present results from a linear probability as supplementary results in the Appendix.

${ }^{9}$ The interaction term follows research illustrating how certain institutional expenditures benefit economically disadvantaged students more than economically advantaged students (Webber and Ehrenberg 2010).
} 


\subsection{Economic Sorting}

To assess the extent to which economically advantaged students in Wisconsin sort into universities with the highest per-student state appropriations, I estimate a bivariate, ordinary least squares regression model of per-student state appropriations using the proportion of years on FRPL as the sole predictor. For this model, I use the same analytic sample as used when estimating the effect of state appropriations on persistence in Wisconsin. The purpose is purely descriptive, simply to show how economically advantaged and disadvantaged students differ in terms of mean per-student state appropriations. Thus, there is no need to control for additional student characteristics. Furthermore, inferential statistics are meaningless in population-level descriptive analyses, in contrast to causal analyses (Abadie et al. 2020), thus I do not compute a standard error.

\subsection{The Role of Expenditures}

To assess the role that different forms of university expenditures play in the effect or null effect of state appropriations on persistence, I conduct two analyses. First, again clustering standard errors by university, I estimate a similar model as shown in Equation (1) except that the model omits state appropriations and the state appropriations $\times$ economic disadvantage interaction term as predictors, while including three categories of expenditure as measured in IPEDS: academic support, instructional, and student services ${ }^{10}$. Academic support expenditures

\footnotetext{
${ }^{10}$ In analyses not shown, I also estimated the same model but with interaction terms between economic disadvantage and each expenditure category. Interaction terms would be relevant if, for example, the expenditure type had a positive effect on persistently-FRPL students' persistence but a negative effect on that of never-FRPL students, a pattern that a zero main effect might mask. The interaction terms ended up being trivially small (results available upon request), so I present results from the model without them, for the sake of clarity and parsimony.
} 
support the instruction, research, and public service missions of a university. Expenses in this category include academic advising, curriculum development, libraries, audio/visual services, and technology support for instruction. Instructional expenditures are those deemed directly related to instruction, most notably faculty salaries. Student services expenditures are those deemed to contribute to student wellbeing. Expenses in this category include psychological counseling, student organizations, intramural athletics, and registrar activities. I measure each of these expense categories on a per-student level ${ }^{11}$.

After assessing which expenditures substantially influence persistence, I estimate how changes in state appropriations affect these expenditures. To do so, I use an institution-level, panel dataset that includes all of the IPEDS measures for each year in the period of analysis. There is no within-university-year, between-student variation to capture in this analysis, so there is no reason to include student-level data from the WSLDS. With this dataset, I then estimate a linear regression model of each expenditure measure that I find to be conditionally associated with persistence. I include per-student state appropriations as the sole predictor in descriptive analyses, and then add university fixed effects to the model to estimate the causal effect of appropriations on relevant expenditures.

\footnotetext{
${ }^{11}$ These expenditure categories are correlated (pairwise correlations of 0.23 for instruction-service, 0.28 for academic support-service, and 0.82 for instruction-academic support). Thus, including all of them as predictors in the same model may bias estimates of how each one affects persistence. Therefore, I also estimate how each expenditure type affects persistence by estimating three separate models, one per expenditure category, including the same control variables and fixed effects as in the denser model. The marginal coefficient corresponding to each expenditure type is the same to two decimal places whether applying the full model or the models with a single expenditure type. Therefore, I do not expect that the correlation between different expenditure categories substantially biased the estimates of how expenditures affect persistence.
} 


\section{$4 \quad$ Results}

\subsection{Summary of Sample}

As a student-level description, Table 1 shows means and standard deviations of each variable analyzed in this study. Overall, $83 \%$ persist from the first year to the second year. On average, a first-year student attends a UW campus that receives about $\$ 5,200$ in per-student appropriations, but there is considerable variation around that mean (standard deviation $=$ $\$ 3,000)$. The analytic sample does not appear to have unusually high or low academic achievement: the average student in the sample achieved an ACT math score of slightly above 23 (the 67th percentile among all ACT-takers nationwide, including those who forwent postsecondary education) and an ACT English score between 22 and 23 (between the 63rd and 68th percentiles nationwide). However, reflecting the uneven selectivity across Wisconsin's public universities, ACT scores are quite dispersed (standard deviations of 5.1 points for English and 4.6 points for math).

As an institution-level description, Table 2 shows means and standard deviations of state appropriations for each UW campus, across years. The table demonstrates that year-to-year variation in per-student state appropriations is quite wide. At all 13 universities, the standard deviation across years is greater than $10 \%$ of the mean, being a much greater percentage in most cases (as high as $38 \%$ at the La Crosse campus). Consequently, there is sufficient withinuniversity variation in the independent variable to conduct an analysis that includes university fixed effects. 


\subsection{Economic Sorting}

Compared to never-FRPL students, persistently-FRPL students attend UW four-year campuses that receive an average of $\$ 610$ less in per-student state appropriations. This difference is about $12 \%$ of the mean per-student state appropriations $(\$ 5,220)$ and $21 \%$ of the standard deviation of per-student state appropriations $(\$ 2,960)$. Thus, there is economic sorting, with more economically advantaged students attending universities that the state funds more generously.

What explains this economic sorting? Differentially selective admissions criteria likely contribute. The flagship UW campus, Madison, is an outlier in terms of both per-student state appropriations and admissions selectivity. For example, the average ACT score of students (including out-of-state students) admitted to the Madison campus is 29 (CollegeData 2020), which represents the 93rd percentile score nationally. If economically disadvantaged students tend to be especially unable to meet the selective admissions criteria of University of WisconsinMadison, then they will be excluded from the most generously funded campus. Indeed, among persistently-FRPL 11 th graders in Wisconsin, only $1 \%$ score at or above the average ACT score of admitted applicants to the Madison campus, while 13\% of never-FRPL 11 th graders score at or above this threshold (calculations my own, drawn from Wisconsin's Statewide Longitudinal Data System). Therefore, it is likely that economically advantaged individuals disproportionately secure spots at the Madison campus — by far the most selective and generously funded — by adapting to exclusion criteria that are formally class-neutral.

\subsection{Effect of State Appropriations}


Table 3 shows estimates from a logistic regression model of college persistence. Results do not support a substantial effect of state appropriation changes on persistence in Wisconsin. The state appropriations coefficient, representing the estimated effect of per-student state appropriations on never-FRPL students' persistence, is slightly positive but not practically or statistically significant. I compute the marginal effect of state appropriations and find a 0.34 percentage point increase in the probability of persistence per $\$ 1000$ increase in per-student state appropriations. The $95 \%$ confidence interval of this marginal effect estimate $(-0.12$ percentage points to 0.79 percentage points) includes, and does not stray far from, zero.

Results do not support significant effect heterogeneity, either. The logit interaction effect of 0.022 is small, with a $95 \%$ confidence interval (-0.05 to 0.10$)$ that includes zero and is not substantially positive or negative at its extremes. Thus, even though the estimated interaction effect suggests that economically disadvantaged students may benefit slightly more from state appropriations than do economically advantaged students, the estimate is too statistically and practically insignificant to infer such heterogeneity.

\subsection{The Role of Expenditures}

The small estimated effect of increased state appropriations on persistence in Wisconsin is surprising given national, institution-level evidence - reviewed in section 2.3 - that shows a positive effect of per-student expenditures on persistence rates. This evidence either shows instructional and student services expenditures (Webber and Ehrenberg 2010) or academic support expenditures (Gansemer-Topf and Schuh 2006; Ryan 2004) to be the most important expenditure categories. Helping explain the apparent null effect of state appropriations on 
persistence, none of the three mechanisms speculated in section 2.3 appear to hold up to empirical scrutiny in Wisconsin, as I illustrate below.

Which expenditures matter for persistence in Wisconsin, and do boosts in state appropriations cause boosts in these expenditures? Table 4 answers the first question. In Wisconsin, the only expenditures category for which increases appear to have a practically and statistically significant effect on persistence is the academic support category. In terms of marginal effects, a $\$ 1,000$ increase in per-student academic support expenditures is associated with a 2 percentage point increase in the probability of persistence.

Table 5 answers the question of whether changes in state appropriations cause changes in the expenditures that matter for persistence (academic support expenditures). The first column indicates that a university with $\$ 1,000$ more in per-student state appropriations tends to spend \$230 more per student on academic support. Therefore, descriptively, universities with greater state appropriations have greater academic support expenditures, on average. However, the net association between state appropriations and academic support expenditures is, in fact, negative: after including university fixed effects, I find that a $\$ 1,000$ within-university, across-year increase in per-student state appropriations is associated with a $\$ 130$ decrease in per-student academic support expenditures (Table 5, second column). This negative conditional association possibly reflects a pattern where the state government tries to compensate for an institution's loss in private revenue but fails to fill the gap. Regardless of the explanation, the result may help explain why state appropriations have little net association with persistence during the present years of study. In particular, even if increased state appropriations have the potential to improve persistence rates when institutions allocate the funding toward academic support, state 
appropriations were not conditionally positively associated with academic support expenditures among the present sample of universities.

\section{Conclusion}

This study offers two main findings related to postsecondary education in Wisconsin. First, more economically advantaged students tend to sort into the public universities that receive greater per-student state appropriations. Second, university-level changes in state appropriations seem to have little conditional association with persistence in Wisconsin. This study also shows that the second finding may be explained by the fact that university-level increases in state appropriations are not conditionally associated with increases in academic support expenditures, the type of expenditures that matter most for Wisconsin students' persistence.

The results of this study do not present evidence that the Wisconsin state government can easily facilitate or limit EMI based on its allocation of funding across universities. From the only explicit test of EMI at the postsecondary level (Andrew 2017), it is clear that economically advantaged students effectively maintain inequality by disproportionately attending highly selective universities, consistent with neo-Weberian notions of social closure (Parkin 1979). But this study has not yielded evidence that public funding is an accomplice in this social closure. If, for example, peer effects rather than disparities in public funding explain the selective college persistence advantage identified by Andrew (2017) and others, then economically disadvantaged students can secure qualitative educational advantages by attending the most selective public universities, regardless of how evenly the state distributes university funding. In short, the results of this study fail to center state policy in the production of EMI. 
However, caution is necessary when interpreting the results of this study. For at least three reasons, the results leave open the possibility that future slashes in state funding of Wisconsin universities would lead to decreased persistence rates. First, if changes in state appropriations influence persistence more substantially at low base levels of appropriations, then reducing appropriations to levels lower than any observed in the period studied could very well hurt persistence rates. Second, the particulars of how universities allocated state appropriations during the period of study may not generalize in future years: if universities allocated the money in ways conducive only to outcomes other than persistence, then it is still uncertain how much future appropriations could matter for persistence rates if universities allocate the money differently. Economic evidence from other settings and time periods suggests that statewide cuts in appropriations reduce degree attainment rates (Deming and Walters 2018b), thus, there is reason to believe that state appropriations make a difference for persistence if universities allocate the money in particular ways. Finally, despite the measures I have taken to identify the causal relationship between state appropriations and persistence, I cannot rule out certain forms of downward bias. In particular, factors that are directly related to appropriations and inversely related to persistence, or vice versa, would drive downward the estimated effect of appropriations on persistence (as long as the direct and inverse relationships exist conditional on university, cohort, and student-level control variables). In sum, before individuals take action based on the results of this study, they should consider the results alongside prior studies with mostly conflicting results, as well as considering any future studies that will, hopefully, emerge.

\section{References}

Abadie, Alberto, Susan Athey, Guido W. Imbens, and Jeffrey Wooldridge. 2017. When Should You Adjust Standard Errors for Clustering? 24003. Cambridge. 
Abadie, Alberto, Susan Athey, Guido W. Imbens, and Jeffrey M. Wooldridge. 2020. "SamplingBased versus Design-Based Uncertainty in Regression Analysis.” 88(1):265-96. doi: 10.3982/ECTA12675.

Alon, Sigal. 2009. “The Evolution of Class Inequality in Higher Education: Competition, Exclusion, and Adaptation.” American Sociological Review 74(5):731-55. doi: 10.1177/000312240907400503.

Alon, Sigal, and Marta Tienda. 2007. "Diversity, Opportunity, and the Shifting Meritocracy in Higher Education.” American Sociological Review 72(4):487-511. doi: 10.1177/000312240707200401.

Andrew, Megan. 2017. "Effectively Maintained Inequality in U.S. Postsecondary Progress: The Importance of Institutional Reach.” American Behavioral Scientist 61(1):30-48. doi: 10.1177/0002764216682809.

Ayalon, Hanna, Eric Grodsky, Adam Gamoran, and Abraham Yogev. 2008. "Diversification and Inequality in Higher Education: A Comparison of Israel and the United States.” Sociology of Education 81(3):211-41. doi: 10.1177/003804070808100301.

Baum, Sandy, J. Ma, and K. Payea. 2013. "Education Pays 2013.” The College Board. Bettinger, Eric P., Brent J. Evans, and Devin G. Pope. 2013. "Improving College Performance and Retention the Easy Way: Unpacking the ACT Exam.” American Economic Journal: Economic Policy 5(2):26-52. doi: 10.1257/pol.5.2.26.

Boliver, Vikki. 2011. "Expansion, Differentiation, and the Persistence of Social Class Inequalities in British Higher Education.” Higher Education 61(3):229-42. doi: 10.1007/s10734-010-9374-y.

Bound, John, Breno Braga, Gaurav Khanna, and Sarah Turner. 2019. "Public Universities: The 
Supply Side of Building a Skilled Workforce.” RSF: The Russell Sage Foundation Journal of the Social Sciences 5(5):43-66. doi: 10.7758/RSF.2019.5.5.03.

Bound, John, and Sarah Turner. 2007. “Cohort Crowding: How Resources Affect Collegiate Attainment." 91:877-99. doi: 10.1016/j.jpubeco.2006.07.006.

Bowen, William G., Matthew M. Chingos, and Michael S. McPherson. 2009. Crossing the Finish Line: Completing College at America's Public Universities. Princeton, NJ: Princeton University Press.

Briggs, Derek C. 2001. "The Effect of Admissions Test Preparation: Evidence from NELS:88." Chance, 10-18.

CollegeData. 2020. “College Profile: University of Wisconsin - Madison.” Retrieved April 1, 2020 (https:/www.collegedata.com/college/University-of-Wisconsin-Madison).

Cunha, Jesse M., and Trey Miller. 2014. "Measuring Value-Added in Higher Education: Possibilities and Limitations in the Use of Administrative Data." Economics of Education Review 42:64-77. doi: 10.1016/j.econedurev.2014.06.001.

Cuseo, Joe. 2007. "The Empirical Case against Large Class Size: Adverse Effects on the Teaching, Learning, and Retention of First-Year Students.” The Journal of Faculty Development 21(1):5-21.

Cutler, David M., and Adriana Lleras-Muney. 2006. Education and Health: Evaluating Theories and Evidence. National bureau of economic research.

Deming, David J., and Christopher R. Walters. 2018a. The Impact of State Budget Cuts on U.S. Postsecondary Attainment.

Deming, David J., and Christopher R. Walters. 2018b. The Impact of State Budget Cuts on US Postsecondary Attainment. Cambridge. 
Gamoran, Adam, and Robert D. Mare. 1989. "Secondary School Tracking and Educational Inequality: Compensation, Reinforcement, or Neutrality?” American Journal of Sociology 94(5):1146-83.

Gansemer-Topf, Ann M., and John H. Schuh. 2006. "Institutional Selectivity and Institutional Expenditures: Examining Organizational Factors That Contribute to Retention and Graduation.” 47(6):613-42. doi: 10.1007/s11162-006-9009-4.

Gerber, Theodore P., and Sin Yi Cheung. 2008. "Horizontal Stratification in Postsecondary Education: Forms, Explanations, and Implications.” 34:299-318. doi:

10.1146/annurev.soc.34.040507.134604.

Hallinan, Maureen T. 1992. "The Organization of Students for Instruction in the Middle School." Sociology of Education 65(2):114-27.

Karabel, Jerome. 2006. The Chosen: The Hidden History of Admission and Exclusion at Harvard, Yale, and Princeton. Boston: Houghton Mifflin Harcourt.

Kelchen, Robert. 2017. A Look at Pell Grant Recipients' Graduation Rates.

Lucas, Samuel R. 2001. "Effectively Maintained Inequality: Education Transitions, Track Mobility, and Social Background Effects.” American Journal of Sociology 10(6):1642-90. doi: $10.1086 / 321300$.

Ma, Jennifer, Sandy Baum, Matea Pender, and D'Wayne Bell. 2015. Trends in College Pricing, 2015. Trends in Higher Education Series.

Mare, Robert D. 1980. "Social Background and School Contiunation Decisions." Journal of the American Statistical Association 75(370):295-305.

Michelmore, Katherine, and Susan M. Dynarski. 2017. “The Gap Within the Gap: Using Longitudinal Data to Understand Income Differences in Educational Outcomes." AERA 
Open 3(1):2332858417692958. doi: 10.1177/2332858417692958.

Parkin, Frank. 1979. Marxism and Class Theory: A Bourgeois Critique. London: Tavistock. Raftery, Adrian E., and Michael Hout. 1993. "Maximally Maintained Inequality: Expansion, Reform, and Opportunity in Irish Education, 1921-75." Sociology of Education 66(1):4162. doi: $10.2307 / 2112784$.

Roksa, Josipa, Eric Grodsky, Richard Arum, and Adam Gamoran. 2007. "United States: Changes in Higher Education and Social Stratification." Pp. 165-91 in Stratification in higher education: A comparative study, edited by Y. Shavit, R. Arum, and A. Gamoran. Stanford: Stanford University Press.

Ryan, John F. 2004. "The Relationship between Institutional Expenditures and Degree Attainment at Baccalaureate Colleges." 45(2):97-114.

Shapiro, Doug, Afet Dundar, Xin Yuan, Autumn T. Harrell, Justin C. Wild, and Mary B. Ziskin. 2014. Some College, No Degree: A National View of Students with Some College Enrollment, but No Completion.

Shavit, Yossi, Richard Arum, and Adam Gamoran. 2007. Stratification in Higher Education: A Comparative Study. Stanford: Stanford University Press.

Small, Mario L., and Christopher Winship. 2007. "Black Students' Graduation from Elite Colleges: Institutional Characteristics and between-Institution Differences." Social Science Research 36(3):1257-75. doi: 10.1016/j.ssresearch.2006.06.006.

Smith, Theresa Y. 1995. “The Retention Status of Underrepresented Minority Students: An Analysis of Survey Results from Sixty-Seven U.S. Colleges and Universities." in Association for Institutional Research Annual Forum. Boston, MA.

State Higher Education Executive Officers Association. 2019. State Higher Education Finance: 
FY 2018. Boulder, CO.

Thomsen, Jens Peter. 2015. "Maintaining Inequality Effectively? Access to Higher Education

Programmes in a Universalist Welfare State in Periods of Educational Expansion 19842010.” European Sociological Review 31(6):683-96. doi: 10.1093/esr/jcv067.

Thomsen, Jens Peter. 2018. “Test-Based Admission to Selective Universities: A Lever for FirstGeneration Students or a Safety Net for the Professional Classes?" Sociology 52(2):333-50. doi: $10.1177 / 0038038516653097$.

Titus, Marvin A. 2006. "Understanding the Influence of the Financial Context of Institutions on Student Persistence at Four-Year Colleges and Universities.” Journal of Higher Education 77(2):353-75. doi: 10.1353/jhe.2006.0009.

U.S. Department of Agriculture. 2015. "Child Nutrition Programs-Income Eligibility Guidelines.” Federal Register 80:9-10.

University of Wisconsin System. 2020. "Budget \& Planning: Tuition.” Retrieved April 29, 2020 (https://www.wisconsin.edu/budget-planning/tuition/).

Urban Institute. 2017. "Understanding College Affordability: The Cost of Educating Students." Retrieved May 8, 2020 (http://collegeaffordability.urban.org/cost-of-educating/index.html). Webber, Douglas A. 2016. “Are College Costs Worth It? How Ability, Major, and Debt Affect the Returns to Schooling." Economics of Education Review 53:296-310.

Webber, Douglas A., and Ronald G. Ehrenberg. 2010. "Do Expenditures Other than Instructional Expenditures Affect Graduation and Persistence Rates in American Higher Education?” Economics of Education Review 29(6):947-58. doi: 10.1016/j.econedurev.2010.04.006.

Zhang, Liang. 2009. "Does State Funding Affect Graduation Rates at Public Four-Year Colleges and Universities?" Educational Policy 23(5):714-31. doi: 10.1177/0895904808321270. 


\section{Tables}

Table 1. Means and standard deviations of measures analyzed in the present study. State appropriations and all expenditures are inflation-adjusted (using the Consumer Price Index) to 2018 dollars and measured per-student.

\begin{tabular}{rrr}
\hline & Mean & SD \\
\hline Persisted 1st to 2nd Year & .83 & .37 \\
State Appropriations & 5,220 & 2,960 \\
Academic Support Expenditures & 2,630 & 1,200 \\
Instructional Expenditures & 8,770 & 3,300 \\
Student Services Expenditures & 2,700 & 450 \\
Proportion of Years FRPL & .14 & .31 \\
White (Non-Hispanic) & .87 & .33 \\
Black (Non-Hispanic) & .04 & .18 \\
Hispanic & .04 & .19 \\
Other/Multiple Race & .06 & .23 \\
Female & .53 & .5 \\
Ever Suspended in High School & .04 & .2 \\
ACT English Score & 22.72 & 5.05 \\
ACT Math Score & 23.16 & 4.62 \\
Proportion Blue Collar & .25 & .08 \\
Rural High School & .24 & .43 \\
\hline
\end{tabular}


Table 2. Means and standard deviations of per-student state appropriations at each UW campus, between 2008-09 and 2017-18. Per-student state appropriations are inflation-adjusted (using the Consumer Price Index) to reflect 2018 dollars.

\begin{tabular}{rrrr}
\hline & Mean & SD & SD/Mean \\
\hline Madison & 11,100 & 1,510 & 0.14 \\
Superior & 8,850 & 960 & 0.11 \\
Parkside & 6,190 & 730 & 0.12 \\
Milwaukee & 5,090 & 550 & 0.11 \\
Green Bay & 4,300 & 690 & 0.16 \\
Stevens Point & 4,190 & 820 & 0.20 \\
River Falls & 4,050 & 700 & 0.17 \\
Eau Claire & 3,940 & 1,030 & 0.26 \\
Oshkosh & 3,830 & 660 & 0.17 \\
Stout & 3,790 & 730 & 0.19 \\
La Crosse & 2,920 & 1,110 & 0.38 \\
Platteville & 2,720 & 830 & 0.31 \\
Whitewater & 2,680 & 960 & 0.36 \\
\hline
\end{tabular}


Table 3. Point estimates, standard errors, and confidence intervals from a logistic regression model of first-to-second year persistence. For brevity, the table does not report university, year, or high school fixed effects.

\begin{tabular}{rccc}
\hline & Coefficient & Std. Err. & $95 \%$ Conf. Int. \\
\hline State Appropriations & 0.02 & 0.02 & $-0.02-0.07$ \\
Proportion of Years FRPL & -0.47 & 0.16 & $-0.78--0.15$ \\
State Appropriations $\times$ Proport. of Years FRPL & 0.02 & 0.04 & $-0.05-0.10$ \\
Black (Non-Hispanic) & -0.05 & 0.04 & $-0.12-0.04$ \\
Hispanic & -0.09 & 0.04 & $-0.18-0.00$ \\
Other/Multiple Race & 0.10 & 0.04 & $0.01-0.19$ \\
Female & 0.30 & 0.03 & $0.24-0.37$ \\
ACT English Score & 0.03 & 0.01 & $0.00-0.05$ \\
ACT English Score (sq.) & -0.00 & 0.00 & $-0.00-0.00$ \\
ACT Math Score & 0.04 & 0.02 & $0.01-0.08$ \\
ACT Math Score (sq.) & -0.00 & 0.00 & $-0.00-0.00$ \\
Ever Suspended in High School & -0.56 & 0.06 & $-0.68--0.45$ \\
Constant & 0.43 & 0.46 & $-0.47-1.33$ \\
\hline
\end{tabular}


Table 4. Point estimates, standard errors, and confidence intervals from a logistic regression model of first-to-second year persistence, with expenditures as the key independent variables rather than state appropriations. For brevity, the table does not report university, year, or high school fixed effects.

\begin{tabular}{rccc}
\hline & Coefficient & Std. Err. & $95 \%$ Conf. Int. \\
\hline Academic Support Expenditures & 0.17 & 0.07 & $0.02-0.32$ \\
Instructional Expenditures & -0.01 & 0.05 & $-0.10-0.08$ \\
Student Services Expenditures & -0.07 & 0.16 & $-0.39-0.24$ \\
Proportion of Years FRPL & -0.37 & 0.04 & $-0.46--0.29$ \\
Black (Non-Hispanic) & -0.04 & 0.04 & $-0.12-0.04$ \\
Hispanic & -0.08 & 0.05 & $-0.17-0.00$ \\
Other/Multiple Race & 0.10 & 0.04 & $0.02-0.19$ \\
Female & 0.30 & 0.03 & $0.24-0.37$ \\
ACT English Score & 0.03 & 0.01 & $0.00-0.05$ \\
ACT English Score (sq.) & -0.00 & 0.00 & $-0.00-0.00$ \\
ACT Math Score & 0.06 & 0.00 & $0.05-0.06$ \\
ACT Math Score (sq.) & -0.00 & 0.00 & $-0.00-0.00$ \\
Constant & -0.56 & 0.06 & $-0.68--0.45$ \\
Ever Suspended in High School & 0.25 & 0.68 & $-1.09-1.59$ \\
\hline
\end{tabular}


Table 5. Estimates from linear regression models of per-student academic support expenditures with (first column) and without (second column) university fixed effects. For brevity, the table does not report university fixed effects.

\begin{tabular}{rcccc}
\hline & \multicolumn{2}{c}{$\begin{array}{c}\text { Without Fixed } \\
\text { Effects }\end{array}$} & \multicolumn{2}{c}{$\begin{array}{c}\text { With Fixed } \\
\text { Effects }\end{array}$} \\
\hline & Coef. & Std. Err & Coef. & Std. Err \\
\hline State Appropriations & 0.23 & 0.02 & -0.13 & 0.02 \\
Constant & 1.26 & 0.13 & 6.62 & .27 \\
\hline
\end{tabular}




\section{Appendix}

Table A1. Point estimates, standard errors, and confidence intervals from a linear probability model of first-tosecond year persistence. Estimates are expressed in percentage points rather than in probability units. For brevity, the table does not report university, year, or high school fixed effects.

\begin{tabular}{rccc}
\hline & Coefficient & Std. Err. & $95 \%$ Conf. Int. \\
\hline State Appropriations & -0.42 & 0.28 & $-1.02-0.18$ \\
Proportion of Years FRPL & -9.41 & 0.95 & $-11.48--7.33$ \\
State Appropriations $\times$ Proportion of Years FRPL & 0.77 & 0.18 & $0.38-1.15$ \\
Black (Non-Hispanic) & -1.17 & 0.90 & $-3.14-0.79$ \\
Hispanic & -1.51 & 0.66 & $-2.96--0.07$ \\
Other/Multiple Race & 1.47 & 0.61 & $0.13-2.80$ \\
Female & 3.70 & 0.55 & $2.50-4.89$ \\
ACT English Score & 0.92 & 0.17 & $0.56-1.28$ \\
ACT English Score (sq.) & -0.02 & 0.00 & $-0.02--0.01$ \\
ACT Math Score & 1.79 & 0.31 & $1.12-2.46$ \\
ACT Math Score (sq.) & -0.02 & 0.01 & $-0.04--0.01$ \\
Ever Suspended in High School & -9.80 & 0.98 & $-11.92--7.67$ \\
Constant & 49.02 & 6.00 & $35.95-62.10$ \\
\hline
\end{tabular}

